\title{
Sistema de classificação dos meios de hospedagem no Brasil: categoria hotéis
}

\author{
Valdicleia Aparecida Ferreira - Mestra em Psicologia - Faculdade de Tecnologia Senac Caçador - Brasil -valdicleia@conection.com.br \\ Elis Regina Mazzurana - Mestra em Produção Vegetal. Faculdade de Tecnologia Senac Caçador - Brasil. elismazzurana@gmail.com \\ Antonio Pedro Tessaro - Mestre em Engenharia. Faculdade de Tecnologia Senac Caçador - Brasil. tessaro@gegnet.com.br \\ Scheine Neis Alves da Cruz De Bastiani - Mestra em Administração. Faculdade de Tecnologia Senac Caçador - Brasil. scheine@sc.senac.br
}

\section{RESUMO}

Este artigo apresenta o sistema de classificação dos meios de hospedagem do Brasil, para os mais diversos tipos de meios de hospedagem, levando em consideração as exigências do Ministério do Turismo em função de determinados requisitos que podem classificar em uma, duas, três, quatro ou cinco estrelas. Este trabalho teve por objetivo conhecer sobre os sistemas de classificação no mundo e mais detalhadamente do Brasil, focado no ramo da hotelaria. $\mathrm{O}$ trabalho foi realizado mediante pesquisa bibliográfica em diversas fontes do setor, onde os critérios de classificação se mostraram uniformes. Apresentou-se em forma de quadro compilado, os critérios de classificação dos meios de hospedagem no Brasil, comparando de forma direta cada um destes nas diferentes classificações. A partir destas, o cliente tem a possibilidadde de optar por um meio de hospedagem que contemple ou satisfaça suas necessidades em termos pessoais ou profissionais.

Palavras-chave: Classificação. Critérios. Meios de Hospedagem.

\section{System of classification of accommodation in Brazil: category hotels}

\begin{abstract}
This article presents the classification system for the accommodation industry in Brazil, for the most diverse types facilities, taking into account the requirements established by the Ministry of Tourism. These requirements can classify hotels in one, two, three, four or five stars. The study aimed to learn about the classification systems in the world and more specifically in Brazil, focusing on the hotel industry. It was carried out via bibliographical research on various sources of this specific area, where the criteria have proved to be uniform. The criteria for classification of hotels in Brazil was presented in the form of compiled chart, directly comparing items in different classifications. Based on such criteria, customers can choose among the items the ones that meet their specific needs in terms of accommodation.
\end{abstract}

Keywords: Classification. Criteria. Accommodation. 


\section{INTRODUÇÃO}

A classificação dos hotéis, por meio do número de estrelas, começou na Europa e se deslocou para o restante do mundo (DUARTE, 2005). De acordo com Castelli (2006), conforme a rede hoteleira crescia gradativamente e ganhava força em meio ao turismo e viajantes, percebeuse a necessidade de garantir para o cliente qualidade no método de hospedagem. Assim, no final da década de 1960, deu-se início a classificação oficial dos meios de hospedagem, no intuito de orientar os clientes a respeito do que este encontraria no hotel desejado, além de contribuir para que proprietários de hotéis tivessem conhecimento sobre as necessidades de adequações de seus estabelecimentos para atender ao padrão de estrelas (CASTELLI, 2006).

Já no Brasil, a história da classificação dos empreendimentos hoteleiros remete ao final da década de 1970, e está ligada à Empresa Brasileira de Turismo - Embratur, criada em 1966 para controlar as atividades e empreendimentos turísticos no Brasil. Em 1975, a Embratur passou a fazer a classificação dos empreendimentos hoteleiros de maneira a orientar o consumidor e tal classificação passou a ser obrigatória em 1977 (CANDEIA, 2003).

Por meio de uma ação conjunta entre o Ministério do Turismo e o Ministério do Desenvolvimento, Indústria e Comércio Exterior foi instituído o Sistema Brasileiro de Classificação dos Meios de Hospedagem, conhecido como SBClass, cumprindo a função de um meio de gestão da informação.

A Classificação dos Meios de Hospedagem é, reconhecidamente, um instrumento de divulgação de informações claras e objetivas a respeito desse setor, sendo um importante mecanismo de comunicação com o mercado. O sistema de classificação dos meios de hospedagem é uma forma de categorizar hotéis de todo o Brasil (PETROCCHI, 2007).

Com relação à importância da classificação dos meios de hospedagem, Petrocchi (2007) relata que consiste no fato de que esta classificação permite estimular o turismo do país, colocando os hotéis no mesmo patamar dos hotéis de outros países, ou seja, em uma categoria equivalente aos hotéis dos melhores lugares do mundo e ainda, possibilitando a concorrência justa entre os meios de hospedagem do país, auxiliando turistas, brasileiros e estrangeiros, em suas escolhas.

Em relação ao seu objetivo, Petrocchi (2007) revela que a classificação serve para orientar o mercado no que se refere às categorias de hotéis que compõem a oferta turística do país e, é por meio desses critérios, que são analisados os meios de hospedagem. Também, a classificação oficial dos meios de hospedagem do Brasil tem como objetivo principal orientar os turistas sobre os aspectos físicos e operacionais que podem ser encontrados nos diversos tipos e categorias nesses estabelecimentos. Para os gestores dos empreendimentos, o objetivo do sistema é de orientar sobre os requisitos que estes estabelecimentos devem possuir para alcançar determinados padrões (MINISTÉRIO DO TURISMO, 2010). Assim sendo, torna-se importante ter um breve panorama a respeito dos sistemas de classificação no mundo, subsidiando um olhar mais focado sobre os sistemas de classificação no Brasil.

\subsection{Objetivo geral}

Conhecer os sistemas de classificação no mundo com um olhar para o Brasil, bem como os requisitos de classificações dos meios de hospedagem. 


\subsection{Objetivos específicos}

Descrever o sistema brasileiro de classificação e seus requisitos;

Apresentar o processo de avaliação para classificação dos meios de hospedagem;

Estabelecer os requisitos de classificação para os hotéis.

\section{SISTEMA DE CLASSIFICAÇÃO DOS MEIOS DE HOSPEDAGEM NO MUNDO}

Vários países, tais como França, Portugal, Alemanha, Suíça, Dinamarca, Chile, Suécia e outros, possuem um sistema de classificação dos meios de hospedagem, utilizados geralmente, como estratégia para promover e assegurar a sua competitividade em um mercado global altamente disputado (MINISTÉRIO DO TURISMO, 2010).

De acordo com o Ministério do Turismo (2010), a maioria dos sistemas de classificação de outros países, assim como o Sistema Brasileiro de Classificação, é de adesão e adoção voluntárias pelos meios de hospedagem.

Santos e Kadota (2012, p. 218) afirmam que "o sistema de classificação hoteleira mais difundido é o de estrelas, que tradicionalmente conta com cinco categorias". Eles ainda explicam que durante algum tempo o sistema de classificação por estrelas causou certa confusão para os turistas.

Duarte (2005) resume o tipo de classificação de hospedagem americana como sendo aquela cuja classificação é definida pelo próprio hoteleiro e é baseada no preço das diárias. Já Cruz e Freitas (2009) destacam que nos Estados Unidos o sistema de classificação referência é o Mobil e a classificação das estrelas vai de uma até cinco, incluindo inspeções de instalações e avaliação de serviços.

O sistema de classificação de meios de hospedagem da França varia de zero a quatro estrelas, sendo o mesmo por adesão voluntária. Na Espanha, não há um sistema nacional, mas sim regional de classificação em que a mesma obedece uma legislação própria. Na Itália a classificação é obrigatória e os níveis vão de uma a cinco estrelas (CRUZ; FREITAS, 2009).

De acordo com Cruz e Freitas (2009) no sistema da rede hoteleira europeia, pode-se destacar os países Itália e França, uma vez que possuem um sistema único e nacional de classificação hoteleira sendo essa obrigatória. Cada região se torna autônoma, ou seja, depende de cada uma delas designar um órgão público que tenha capacidade de controlar esse sistema, responsabilizando-se pela mesma, levando em consideração que o país em si não se responsabiliza por todas as regiões no requisito de classificação de hotéis. A partir dos anos de 1990, foi elaborada uma nova proposta de classificação de hotéis, adotando alguns padrões essenciais obrigatórios para cada categoria. Leva-se em consideração para selecionar a categoria (estrelas) os seguintes itens: horários, dimensões e qualidade de instalações e serviços, além do que cada estabelecimento oferece, que o caracteriza de forma diferencial.

Os hotéis chineses são classificados por estrelas, de três a cinco estrelas, que são dadas de acordo com a qualidade e condições físicas dos serviços, medidas por meio das seguintes categorias: instalações necessárias e gama de serviços; qualidade das instalações e equipamentos; manutenção; limpeza; qualidade dos serviços e satisfação dos hóspedes. Na seção de instalações necessárias e gama de serviços, os hotéis são dotados de estrelas de acordo com as instalações e serviços oferecidos, enquanto nas outras seções é dada uma pontuação para cada item oferecido pelo hotel e conforme a pontuação vai alterando-se as estrelas do hotel (CRUZ; FREITAS, 2009). 


\subsection{O sistema brasileiro de classificação e seus requisitos}

O sistema de classificação está em vigor no Brasil desde o ano de 2002, mas devido à baixa adesão, o Ministério do Turismo sancionou a portaria no 100, de 16 de junho de 2011, que estabelece um novo modelo, onde os meios de hospedagem são classificados em sete tipos: hotel, resort, hotel fazenda, cama e café, hotel histórico, pousada e flat/apart hotel (BRASIL, 2011).

Todos os locais recebem a classificação de uma (1) a cinco (5) estrelas, conforme legislação regida pelo Ministério do Turismo, e acompanhadas por instituições legalmente organizadas. Considera que cada tipo de meio de hospedagem reflete diferentes práticas de mercado e expectativas distintas dos turistas. Assim, o SBClass estabeleceu categorias específicas para cada um dos 7 tipos de estabelecimentos (MINISTÉRIO DO TURISMO, 2010), sendo que os requisitos definidos para as categorias de cada tipo estão estabelecidos nas Matrizes de Classificação e abrangem os seguintes aspectos: serviços prestados, qualidade da infraestrutura de instalações e equipamentos; e variáveis e fatores relacionados com o desenvolvimento sustentável, tais como conceitos ambientais, relações com a sociedade, satisfação do usuário, dentre outros (BRASIL, 2011).

De acordo com a portaria, a classificação dos meios de hospedagem fica estabelecida da seguinte forma: hotel (de 1 a 5 estrelas); resort ( 4 a 5 estrelas); hotel fazenda ( 1 a 5 estrelas); cama e café ( 1 a 4 estrelas); hotel histórico ( 3 a 5 estrelas); pousada ( 1 a 5 estrelas), e flat/apart hotel ( 3 a 5 estrelas). É importante salientar que o novo Sistema Brasileiro de Classificação utiliza a já consagrada simbologia de estrelas para diferenciar as categorias e é de adesão e adoção voluntárias pelos proprietários dos meios de hospedagem.

As matrizes com os respectivos requisitos, apresentam um conteúdo que atende desde os meios de hospedagem maiores e luxuosos aos mais simples, tornando-se para os empreendimentos menores uma boa oportunidade de destaque e reconhecimento.

\subsubsection{Requisitos avaliados}

De acordo com o Ministério do Turismo (2010) o Sistema Brasileiro de Classificação está fundamentado em uma série de requisitos, os quais os meios de hospedagem devem atender:

- Infraestrutura: vinculados às instalações e aos equipamentos;

- Serviços: vinculados à oferta de serviços;

- Sustentabilidade: vinculados às ações de sustentabilidade (uso dos recursos, de maneira ambientalmente responsável, socialmente justa e economicamente viável, de forma que o atendimento das necessidades atuais não comprometa a possibilidade de uso pelas futuras gerações).

Os requisitos são divididos em mandatórios, que são aqueles de cumprimento obrigatório pelo meio de hospedagem; e eletivos, que são aqueles de livre escolha do meio de hospedagem, tendo como base uma lista pré-definida (MINISTÉRIO DO TURISMO, 2010).

Para ser classificado na categoria pretendida, o meio de hospedagem precisa ser avaliado por um representante legal do Instituto Nacional de Metrologia, Qualidade e Tecnologia - Inmetro, e demonstrar o atendimento a 100\% dos requisitos mandatórios e a - no mínimo - 30\% dos requisitos eletivos para cada conjunto de requisitos (MINISTÉRIO DO TURISMO, 2010).

De acordo com estudos de Teles (2011), o SBClass foi um instrumento utilizado para orientar a preparar o país para a Copa de 2014 e também para as Olimpíadas de 2016. Os órgãos responsáveis pela classificação dos meios de hospedagens no Brasil, são o Ministério do Turismo 
(Mtur), o Instituto Brasileiro do Turismo (Embratur) e a Associação Brasileira da Indústria de Hotéis $(\mathrm{ABIH})$.

\subsubsection{Processo de avaliação para classificação dos meios de hospedagem}

Para que os meios de hospedagem possam realizar a avaliação de classificação, o Ministério do Turismo (2010) estabelece algumas etapas que devem ser seguidas pelos meios de hospedagem:

1a etapa: Preencher o formulário eletrônico de solicitação da classificação no site do Cadastur: www.cadastur.turismo.gov.br;

2a etapa: Preencher os documentos: termo de compromisso, declaração do fornecedor e autoavaliação;

$3^{\text {a }}$ etapa: Encaminhar os documentos: termo de compromisso, declaração do fornecedor e auto avaliação, ao Órgão Oficial de Turismo da Unidade da Federação onde estiver localizado o meio de hospedagem;

4a etapa: O Órgão Oficial de Turismo vai analisar a solicitação e verificar a conformidade da documentação enviada pelo meio de hospedagem em até 10 dias corridos;

5a etapa: Se a solicitação e a documentação estiverem corretas, o Órgão Oficial de Turismo encaminha o comunicado da abertura do processo, via sistema Cadastur, ao meio de hospedagem e ao representante legal do Inmetro da Unidade da Federação onde estiver localizado o meio de hospedagem. Caso a documentação não esteja correta, o Órgão Oficial de Turismo encaminha o comunicado sobre as incorreções, via sistema Cadastur, ao meio de hospedagem. Este deve fazer as correções devidas em até 60 dias corridos e encaminhá-las ao Órgão Oficial de Turismo;

6a etapa: O representante legal do Inmetro emitirá, em sistema próprio, a Guia de Recolhimento da União (GRU), com os valores a serem pagos e enviará ao meio de hospedagem via sistema Cadastur.

7a etapa: O representante legal do Inmetro definirá o avaliador e agendará a avaliação inicial, via sistema, em comum acordo com o meio de hospedagem, no prazo de 10 dias corridos;

$8^{\text {a }}$ etapa: O representante legal do Inmetro realizará a avaliação no meio de hospedagem de acordo com as informações fornecidas por ele na autoavaliação;

9a etapa: O representante legal do Inmetro, após a avaliação, informará o resultado e entregará o registro preliminar, incluindo as conformidades e não conformidades constatadas;

10a etapa: O representante legal do Inmetro, em até 15 dias corridos, a contar da data da avaliação, emitirá o relatório final ao meio de hospedagem avaliado, incluindo detalhadamente as não conformidades, se encontradas, de modo que possam ser definidas as ações corretivas. Nos casos de não conformidades, o representante legal do Inmetro deverá acordar com o meio de hospedagem o prazo e a forma para apresentar as evidências de ações tomadas para atendimento aos requisitos da matriz e retornar ao local, se for o caso, em até 90 dias da data da avaliação. No caso de impossibilidade das ações corretivas, por falta de conformidade, o processo deverá ser encerrado pelo representante legal do Inmetro e comunicado via sistema aos interessados.

$11^{\text {a }}$ etapa: Caso não ocorram inconformidades, ou estas sejam sanadas dentro do tempo estipulado na etapa 9, o Ministério do Turismo, com base no relatório final de verificação, emitirá o certificado de classificação e concederá autorização para o uso da marca da classificação de meios de hospedagem. 


\subsubsection{Categoria: hotéis}

O hotel de categoria uma estrela precisa atender a requisitos mínimos de infraestrutura, serviços e sustentabilidade. Para cada estrela adicional, o hotel deve atender a uma série de requisitos adicionais que diferenciam as categorias entre si. Por meio da comparação entre a infraestrutura e serviços oferecidos, assim como das ações de sustentabilidade executadas pelo meio de hospedagem, o consumidor poderá fazer a escolha, de acordo com suas necessidades (MINISTÉRIO DO TURISMO, 2010).

O Quadro 1 apresenta os requisitos obrigatórios para classificação dos hotéis, de acordo com a portaria n 100, de 16 de junho de 2011 (BRASIL, 2011).

Quadro 1 - Requisitos obrigatórios para classificação dos hotéis

\begin{tabular}{|c|c|c|c|c|c|}
\hline Item & $\begin{array}{l}\text { Hotel } 1 \\
\text { estrela }\end{array}$ & $\begin{array}{l}\text { Hotel } 2 \\
\text { estrelas }\end{array}$ & $\begin{array}{l}\text { Hotel } 3 \\
\text { estrelas }\end{array}$ & $\begin{array}{l}\text { Hotel } 4 \\
\text { estrelas }\end{array}$ & $\begin{array}{l}\text { Hotel } 5 \\
\text { estrelas }\end{array}$ \\
\hline Recepção & $\begin{array}{l}\text { Aberta } 12 \\
\text { horas e } \\
\text { acessivivel } 24 \\
\text { horas }\end{array}$ & $\begin{array}{l}\text { Aberta } 12 \\
\text { horas e } \\
\text { acessível } 24 \\
\text { horas }\end{array}$ & $\begin{array}{l}\text { Aberto por } \\
18 \text { horas e } \\
\text { acessível por } \\
\text { telefone } \\
\text { durante } 24 \\
\text { horas }\end{array}$ & $\begin{array}{l}\text { Serviço de } \\
\text { recepção } \\
\text { aberto por } 24 \\
\text { horas }\end{array}$ & $\begin{array}{l}\text { Serviço de } \\
\text { recepção } \\
\text { aberto por } 24 \\
\text { horas }\end{array}$ \\
\hline Serviço de mensageiro & & & $\begin{array}{l}\text { Serviço de } \\
\text { mensageiro } \\
\text { no período } \\
\text { de } 16 \text { horas } \\
\end{array}$ & $\begin{array}{l}\text { Serviço de } \\
\text { mensageiro } \\
\text { no período } \\
\text { de } 24 \text { horas }\end{array}$ & $\begin{array}{l}\text { Serviço de } \\
\text { mensageiro } \\
\text { no período } \\
\text { de } 24 \text { horas } \\
\end{array}$ \\
\hline Área útil da Unidade Habitacional (UH) & $\begin{array}{l}\text { Área útil da } \\
\text { UH, exceto } \\
\text { banheiro, } \\
\text { com } 9 \mathrm{~m}^{2} \\
\text { (em no } \\
\text { mínimo 65\% } \\
\text { das UH) }\end{array}$ & $\begin{array}{l}\text { Área útil da } \\
\text { UH, exceto } \\
\text { banheiro, } \\
\text { com } 11 \mathrm{~m}^{2} \\
\text { (mínimo } \\
70 \% \text { ) }\end{array}$ & $\begin{array}{l}\text { Área útil da } \\
\text { UH, exceto } \\
\text { banheiro, } \\
\text { com } 13 \mathrm{~m}^{2} \\
\text { (mínimo } \\
80 \% \text { ) }\end{array}$ & $\begin{array}{l}\text { Área útil da } \\
\text { UH, exceto } \\
\text { banheiro, } \\
\text { com } 15 \mathrm{~m}^{2} \\
\text { (mínimo } \\
90 \% \text { ) }\end{array}$ & $\begin{array}{l}\text { Área útil da } \\
\text { UH, exceto } \\
\text { banheiro, } \\
\text { com } 17 \mathrm{~m}\end{array}$ \\
\hline $\begin{array}{l}\text { Serviço de cofre para guarda dos valores dos } \\
\text { hospedes }\end{array}$ & & & & $100 \%$ das UH & $100 \%$ das UH \\
\hline Banheiros & $\begin{array}{l}\text { Banheiros } \\
\text { nas UH com } 2 \\
\mathrm{~m}^{2} \text { (em no } \\
\text { mínimo 65\% } \\
\text { das UH) }\end{array}$ & $\begin{array}{l}\text { Banheiro nas } \\
\text { UH com } 2 \mathrm{~m}^{2} \\
\text { (em no } \\
\text { mínimo } 70 \% \\
\text { das UH) }\end{array}$ & $\begin{array}{l}\text { Banheiro nas } \\
\text { UH com } 3 \mathrm{~m}^{2} \\
\text { (mínimo } \\
80 \% \text { das UH }\end{array}$ & $\begin{array}{l}\text { Banheiros } \\
\text { nas UH com } 3 \\
\mathrm{~m}^{2} \text { (mínimo } \\
90 \% \text { ) }\end{array}$ & $\begin{array}{l}\text { Banheiro nas } \\
\text { UH com } 4 \mathrm{~m}^{2}\end{array}$ \\
\hline $\begin{array}{l}\text { Colchões das camas com dimensões superiores } \\
\text { ao padrão nacional }\end{array}$ & & & & & Sim \\
\hline Roupão e chinelo em 100\% das UH & & & & & Sim \\
\hline Banheira & & & & & Sim \\
\hline Berço para bebês & & & & A pedido & A pedido \\
\hline $\begin{array}{l}\text { Facilidades para bebês (cadeiras altas no } \\
\text { restaurante, facilidades para aquecimento de } \\
\text { mamadeiras e comidas etc.); }\end{array}$ & & & & Sim & Sim \\
\hline Café da manhã na UH & & & & Sim & Sim \\
\hline $\begin{array}{l}\text { Serviço de refeições leves e bebidas nas UH } \\
\text { (room service) no período de } 24 \text { horas }\end{array}$ & & & & Sim & Sim \\
\hline Troca de cama & $\begin{array}{l}\text { Uma vez por } \\
\text { semana }\end{array}$ & $\begin{array}{l}\text { Duas vezes } \\
\text { por semana }\end{array}$ & $\begin{array}{l}\text { Dias } \\
\text { alternados }\end{array}$ & Diariamente & Diariamente \\
\hline Troca de roupas de banho & & & Diariamente & Diariamente & Diariamente \\
\hline
\end{tabular}




\begin{tabular}{|c|c|c|c|c|c|}
\hline Secador de cabelo à disposição sob pedido & & & & $\operatorname{Sim}$ & Sim \\
\hline Serviço de lavanderia & & & Sim & Sim & Sim \\
\hline Sala de estar & Não se aplica & $\begin{array}{l}\text { Com } \\
\text { televisão }\end{array}$ & $\begin{array}{l}\text { Com } \\
\text { televisão }\end{array}$ & & \\
\hline Televisão em 100 \% das UH & & & Sim & Sim & Sim \\
\hline Canais de TV por assinatura em $100 \%$ das UH & & & Sim & Sim & Sim \\
\hline Acesso à internet nas áreas sociais e nas UH & & & Sim & Sim & Sim \\
\hline $\begin{array}{l}\text { Mesa de trabalho, com cadeira, iluminação } \\
\text { própria, e ponto de energia e telefone, nas UH, } \\
\text { possibilitando o uso de aparelhos eletrônicos } \\
\text { pessoais; }\end{array}$ & & & & Sim & Sim \\
\hline $\begin{array}{l}\text { Sala de ginástica/musculação com } \\
\text { equipamentos }\end{array}$ & & & & Sim & Sim \\
\hline Serviço de facilidades de escritório virtual & & & Sim & Sim & Sim \\
\hline Mini refrigerador em $100 \%$ das UH & & & Sim & Sim & Sim \\
\hline $\begin{array}{l}\text { Climatização (refrigeração/ventilação } \\
\text { forçada/calefação) adequada em 100\% das UH; }\end{array}$ & & & Sim & Sim & Sim \\
\hline $\begin{array}{l}\text { Salão de eventos; Serviço de "guest relation / } \\
\text { concierge" }\end{array}$ & & & & & Sim \\
\hline Restaurante & & & Sim & Sim & Sim \\
\hline $\begin{array}{l}\text { Serviço de alimentação disponível para café da } \\
\text { manhã, almoço e jantar }\end{array}$ & & & & Sim & Sim \\
\hline Serviço à la carte no restaurante & & & & Sim & Sim \\
\hline Bar & & & & Sim & Sim \\
\hline $\begin{array}{l}\text { Preparação de dietas especiais (vegetariana, } \\
\text { hipocalórica etc.); }\end{array}$ & & & & & Sim \\
\hline $\begin{array}{l}\text { Área de estacionamento com serviço de } \\
\text { manobrista }\end{array}$ & & & & Sim & Sim \\
\hline Café da manhã & Sim & Sim & Sim & Sim & Sim \\
\hline Estacionamento & & & Sim & Sim & Sim \\
\hline $\begin{array}{l}\text { Mínimo de três serviços acessórios oferecidos em } \\
\text { instalações no próprio hotel (por exemplo: salão } \\
\text { de beleza, baby-sitter, venda de jornais e } \\
\text { revistas, farmácia, loja de conveniência, locação } \\
\text { de automóveis, reserva em espetáculos, agência } \\
\text { de turismo, transporte especial etc.) }\end{array}$ & & & & Sim & Sim \\
\hline Programa de treinamento para empregados & & & Sim & Sim & Sim \\
\hline Pagamento com cartão de crédito ou de débito & Sim & Sim & Sim & Sim & Sim \\
\hline $\begin{array}{l}\text { Medidas permanentes para redução do consumo } \\
\text { de energia elétrica e de água }\end{array}$ & Sim & Sim & Sim & Sim & Sim \\
\hline $\begin{array}{l}\text { Medidas permanentes para o gerenciamento de } \\
\text { resíduos sólidos, com foco na redução, } \\
\text { reutilização e reciclagem }\end{array}$ & Sim & Sim & Sim & Sim & Sim \\
\hline $\begin{array}{l}\text { Monitoramento das expectativas e impressões } \\
\text { do hóspede em relação aos serviços ofertados, } \\
\text { incluindo meios para pesquisar opiniões, } \\
\text { reclamações e solucioná-las }\end{array}$ & Sim & Sim & Sim & Sim & Sim \\
\hline $\begin{array}{l}\text { Medidas permanentes de seleção de } \\
\text { fornecedores (critérios ambientais, socioculturais } \\
\text { e econômicos) para promover a sustentabilidade }\end{array}$ & & & & Sim & Sim \\
\hline $\begin{array}{l}\text { Medidas permanentes de sensibilização para os } \\
\text { hóspedes em relação à sustentabilidade }\end{array}$ & & & & Sim & Sim \\
\hline
\end{tabular}

Fonte: Brasil (2011) 


\section{CONCLUSÃO}

É possível verificar que há muitas variações entre as categorias de classificação dos meios de hospedagem, cada uma com as especificidades que precisam ou devem ser atingidas para categorizar o hotel em uma dessas classificações para receber o título ou a estrela adequada ao tipo e qualidade de um meio de hospedagem. Para tanto, seguem-se processos de avaliação, nos quais estão identificados quem avalia e com que frequência.

Desse modo, a classificação segue alguns requisitos como infraestrutura, oferta de serviços e a sustentabilidade. Porém, além disso, parece importante pensar em classificação como algo que também agrega aspectos considerados importantes pelos clientes na hora de escolher seu meio de hospedagem.

Vários dos requisitos apresentados podem ser mais relevantes para um cliente do que para outro, levando-o a escolher um hotel que atenda às suas expectativas. Neste trabalho, compilou-se de forma simples os diferentes requisitos para a classificação no intuito de mostrar quais são os itens obrigatórios que cada hotel deve apresentar de acordo com a categoria a que se encaixa, atendendo as expectativas dos clientes.

\section{REFERÊNCIAS}

BRASIL. Portaria n 100, de 16 de junho de 2011. Institui o Sistema Brasileiro de Classificação de Meios de Hospedagem (SBClass), estabelece os critérios de classificação destes, cria o Conselho Técnico Nacional de Classificação de Meios de Hospedagem (CTClass) e dá outras providências. [2011]. Disponível em: <http://www.turismo.gov.br/legislacao/?p=175>. Acesso em: 04 jan. 2015.

CANDEIA, Débora Lorenzoni. Classificação dos Meios de Hospedagem: a validade para os empreendimentos. 2003. Monografia (especialização) - Universidade de Brasília, Brasília.

CASTELLI, Geraldo. Hospitalidade: na perspectiva da gastronomia e da hotelaria. São Paulo: Saraiva, 2006.

CRUZ, Nina Amélia Chartuni Cabral da; FREITAS, André Luís Policani. Comparações entre sistemas utilizados para classificação de meios de hospedagem. In: Encontro Nacional de Engenharia de Produção, 29., 2009, Salvador. Anais... Salvador: ABEPRO, 2009. Disponível em:

$<$ http://www.abepro.org.br/biblioteca/enegep2009_TN_WIC_092_627_13580.pdf >. Acesso em 04 jul. 2016. p. 1-15.

DUARTE, Valdir Vieira. Administração de sistemas hoteleiros: conceitos básicos 3. ed. São Paulo: Editora Senac, 2005.

MINISTÉRIO DO TURISMO. Sistema brasileiro de classificação de meios de hospedagem: Cartilha de orientação básica. [2010]. Disponível em:

<http://www.classificacao.turismo.gov.br/MTUR-classificacao/mtur-site/ObterClassificacao>. Acesso em: 04 jan. 2015.

PETROCCHI, Mario. Hotelaria: Planejamento e Gestão. 2. ed. São Paulo: Pearson Prentice Hall, 2007.

SANTOS, Glauber Eduardo de Oliveira; KADOTA, Décio Katsushigue. Economia do turismo. São Paulo: Aleph, 2012.

TELES, Reinaldo Miranda de Sá (Org.). Turismo e meio ambiente. Rio de Janeiro: Elsevier, 2011. 